Aslesen, S, Kristensen, E. Schanche, H. and Heen, P. I. (2018). "Winning the bid - a step-wise approach using BIM to reduce uncertainty in construction bidding". In: Proc. $26^{\text {th }}$ Annual Conference of the International. Group for Lean Construction (IGLC), González, V.A. (ed.), Chennai, India, pp. 68-78. DOI: doi.org/10.24928/2018/0229. Available at: www.iglc.net.

\title{
WINNING THE BID - A STEP-WISE APPROACH USING BIM TO REDUCE UNCERTAINTY IN CONSTRUCTION BIDDING
}

\author{
Aslesen, S. ${ }^{1}$, Kristensen, E. ${ }^{2}$, Schanche, H. $^{3}$ and Heen, P. I. ${ }^{4}$
}

\begin{abstract}
This paper explains how to win a construction bid at the right costs. It suggests a structured, step-wise approach where at each step data analyses are carried out based on earlier bids, which are combined with assessments from an active risk management system, to come up with reliable estimates. To make sure all significant cost elements in the project are understood, linked together and communicated effectively, a building information model (BIM) is applied and worked on every step of the way from a preliminary, rough estimation to a final, complete bid.

The paper derives from an ongoing development project to improve the bidding process in a Norwegian construction company. It intends to solve the following problem: How can we reduce the uncertainty in the bids we offer?

The paper introduces a new way to organize the bidding process, including certain principles, to reduce uncertainty already in the project development, and attempts to increase our knowledge of the construction bidding process. The literature review is focused on theories of relevance to address the uncertainties inherent in construction bidding. The paper concludes that a project bid will always be burdened with uncertainty. Whereas traditional bidding theory gives support to the behaviour of economic agents who do the pricing to maximise profit, we find it relevant to introduce the concept of bounded rationality to explain why construction bidding is not a straightforward matter and how uncertainty management is fundamental to come up with the right costs.
\end{abstract}

\section{KEYWORDS}

Uncertainty management, bidding process, BIM.

\footnotetext{
Development Manager, Veidekke, Oslo, Norway, +47 92218 492, sigmund.aslesen@veidekke.no BIM \& Calculation Manager, Veidekke, Oslo, Norway, +47 93455 485, eirik.kristensen@ veidekke.no Dept. Manager, Veidekke, Oslo, Norway, +47 90691 103, hallgeir.schanche@ veidekke.no

Project Development Manager, Veidekke, Oslo, Norway, +47 90151 291, per-inge.heen@ veidekke.no
} 


\section{INTRODUCTION}

The construction industry business is about to win the bid, and to execute the project. But how do we know which are the right projects? During the bidding process, when the project is still in its developing, there is an element of uncertainty which can be particularly high. Uncertainty, however, comes with an upside, too, and not only a downside. Almost no matter the level of detailing at an early stage, there are normally several ways to solve a project. In construction bidding, uncertainty is about taking advantage of these opportunities as well as including risks in the calculation.

This paper reports from an ongoing development project in a construction company, to improve their bidding process. The business unit is part of a major Norwegian construction company. It has a yearly turnover of around 3,3 billion NOK (415 million USD), and where just below 2 per cent or 50 million NOK (6,6 million USD) a year is invested in bidding work. Each year about 30 bids are prepared by the unit. The percentage of projects gained or won vary significantly amongst different markets, although with a total average of between 40 and 50 per cent of the bids being realized each year. Our concern is partly related to the share of projects won, which we think is too low considered the efforts made to win each project, and partly related to the substantial variation between markets in acquired projects. We suspect that the variability in projects won is particularly owed to a lack of standardized procedures in the bidding process.

Bidding, although requiring a highly qualified effort, is fundamentally about making assumptions. In the construction industry, these assumptions are typically based on multiple criteria and various trade-offs, which in turn are transformed into cost estimates. Uncertainty management can be performed to foresee if the project can be influenced by incidents which may have a positive or negative outcome on the results. Even though the project is not yet initiated, one may work to optimize it according to its potential risks and opportunities. In the paper, we describe a step-wise approach to develop a project bid at the right costs. By applying this approach, we expect to speed up our bidding process at the same time as the bids we offer have a higher return rate than today as well as a lower level of uncertainty.

\section{THEORY}

Competitive bidding has been studied for more than 50 years. One of the early, notable contributions to the field is by Friedman (1956) on competitive bidding strategy. It involves maximising the expected profit from a single tender where each competitor submits a closed bid by selecting a mark-up on cost that maximises expected value of the profit - which is the product of the mark-up and the probability of winning the contract (Runeson and Skitmore 1999). The problem, according to Friedman, lies in determining the probability of winning as a function of the mark-up (op.cit). Friedman's competitive bidding strategy has later been reinterpreted by Gates (1967) from a single bid strategy into a general, profit maximising pricing model. An essential characteristic of the model presented by Gates (1967) is a mark-up that is constant, over time and in practice, from 
tender to tender (Runeson and Skitmore 1999). It excludes the possibilities of systematic changes in the mark-up to calculate the probabilities of success at different mark-ups (op.cit.).

Construction bidding is the procedure of submitting a proposal by contractors to carry out a described construction project (Zhu 2008). A construction bidding process normally consists of several contractors competing to perform a job by submitting a sealed proposal until a certain date previously defined by the client (Ribeiro et al. 2013). The usual format of this process is based on the rule that - all other things being equal - the contract will be awarded to the competitor which submits the lowest bid (Cheung et al. 2008). Note that, although increasingly more contracts are being awarded according to factors other than price, awarding contracts to the lowest bidder is still far from having been phased out (Seydel and Oslon 2000). Finding the right price is moreover not a very straightforward matter. The construction industry faces strong levels of price competitiveness (Chao and Liu 2007). The competitive pressures may lead contractors to lower their profit margins to produce a more competitive bid (op.cit). A contractor might also cut the margins for other reasons, such as positioning in a specific market, maintaining long-term client relationships, developing strategically important competence in-house and so on. Whatever reasons it does not rule out the strategic importance of establishing some sort of link between the mark-up level and the probability of winning the bid.

How, then, to determine whether the price is right? In an article by Runeson and Skitmore (1999) the competitive bidding theory is criticized for being inappropriate to describe the construction bidding situation. This is done on two grounds; first, that to maximize the expected value of every single bid may work well for a game of poker or when betting on horses, but the problem in construction tendering is to maximize the return to a given productive capacity. There is almost always a choice of contracts to bid for, and winning a contract means that part of the firm's resources is locked up so that the firm is unable to compete for potentially more profitable contracts. Second, that the theory is based on a failing logic the way it assumes any observed differences in tenders must be unsystematic and due to inaccuracies in the cost estimates. How can it be, then, that ever so often all estimators get it wrong by about the same magnitude and in the same direction and at the same time? This rhetorical question leads the authors to conclude that bidding implies a behaviour that is far removed from the assumption of rationality that is central to most aspects of economic reasoning.

Where does this leave us in terms of finding the right price? It seems that a profitmaximising bidding strategy as a prescribed practice is ill-founded, which may also explain why there is little evidence of its adoption in practice (Runeson and Skitmore 1999). However, if not driven by utility maximisation, then what? Several studies suggest that decisions regarding the definition of the mark-up level are mainly supported using subjective judgment, gut feeling and heuristics (Hartono and Yap 2011). Although this is apparently what happens in many circumstances, we believe that the notion of bounded rationality as coined by Nobel Prize winner Herbert Simon in Models of Man (1957) is more usable to understand agents' actions. According to Simon, people are boundedly 
rational the way they experience limits in formulating and solving complex problems and processing information (op.cit). This does not necessarily mean that people behave irrationally, for instance in their struggle to come up with the right price. In an article by Beckert (1996) on the uncertainty embedded in economic actions it is suggested that people are intentionally rational, but that the existence of uncertainty prevents people from knowing what is best for them to do. Uncertainty is here understood as the character of situations in which agents cannot anticipate the outcome of a decision and cannot assign probabilities to the outcome (op.cit).

If we apply this concept of uncertainty to the bidding process, it is reasonable to question the very existence of such a thing as an optimal price or bid. Partly, because information is often limited, not wholly accurate and missing, and partly because of our insufficient mental capability to make sense and process the information. Rather than searching for the optimal price, finding ways to reduce the uncertainty in the bids we offer may seem like a more appropriate approach to structure the bidding process. At the firm level, the main bidding procedure for a construction company can be separated into two stages: 1) the bid/no bid decision and 2) the mark-up decision (Zhu 2008). The incorporation of uncertainty into these major decisions will necessarily imply a process for generating alternatives, and procedures for estimating them - at the same time accepting the limits of human cognitive capacity for discovering alternatives (Simon 1987). Besides, past bidding information can work as a guideline for future bids. While the accuracy of cost estimates can, by definition, only be assessed in relation to actual costs, it may show useful to apply the real empirical data a contractor compiles concerning earlier bidding competitions where a specific mark-up level is included in the bid proposals. If not to predict the future, then simply to organize past bidding information in a way that is meaningful to current bid decisions (Crowley 2000).

From the Lean Construction domain, Target Value Design (TVD) as a method for setting project targets and steering design and construction toward them can be relevant. TVD is particularly designed for the project delivery process and involves engaging deeply with the client to establish the target value (Tommelein and Ballard 2016). While the bidding process takes place before the project is realized it may often include close collaboration with the client, which is typically the case in private work construction. Besides, even though the client is not involved in the bidding process per se, there are normally several guidelines expressed suggestively by the client in his or her inquiry. A central part of the bidding process, as such, is about to use the client's needs to spur innovation in both product and process design - to reduce costs. To support this innovation process, using Choosing-By-Advantages (CBA) and virtual first-run studies (VFRS) can be highly adequate. CBA is a method for sound decision making which is often used when multiple variables need to be considered to make an informed decision, and where an advantage is a difference between the attributes of two or more alternatives (Suhr 1999). First-run studies is another principle attached to the Lean Construction concept, including trial execution of an operation as a test of capability to meet safety, quality, time and cost targets (Tommelein and Ballard 2016). Traditionally, these studies are done ahead of the scheduled first start of an operation. In the bidding process, they 
may instead take form of virtual prototyping using BIM, to visualize and estimate alternatives, clarify uncertainties, and make decisions.

\section{A STEP-WISE APPROACH TO WIN THE BID}

The step-wise approach to construction bidding presented in figure 1 below is explained in further details in the subsequent sections.

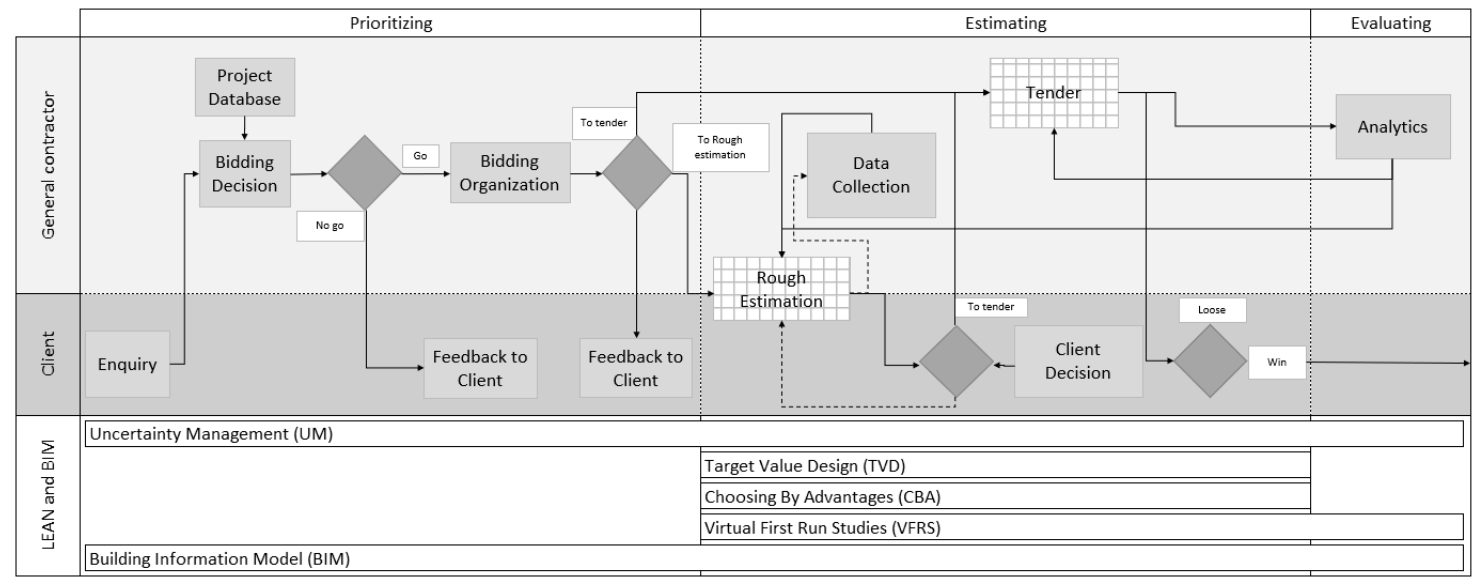

Figure 1 A step-wise approach to construction bidding

\section{TWO STEPS TO BID - ONE STEP TO LEARN}

We suggest the bidding process to be divided in three steps. The division into steps is done to define its main activities, as well as to rapid the process up by pulling it towards a decision point at the end of each step. By this, we hope to make for a more concentrated effort in the bidding work.

The first step we call "prioritizing", where projects are to be chosen based on the unit's business strategy. It goes back to the point that there is almost always a choice of contracts to bid for, and that working to win a contract means that part of our resources is locked up so that we are unable to or less capable of competing for potentially more profitable contracts. Main decision criteria to go further to bidding can be; 1) a reasonable chance to win, 2) good prospects for making a decent profit, 3) strengthen positioning in a market of significant importance, and that we 4) develop in-house competencies. In the work to identify major opportunities and risks, we want to use the active risk management system to apply information from earlier bids. The system describes and quantifies the cost consequences of various uncertainties. The quantification is done by triple estimating the probable outcome of uncertainties, where we operate with worst case, most likely case and best-case scenarios. The system also contains "thick" information about the actions taken to optimize the upsides and reduce the downsides of every uncertainty identified on the project level. The information will be supplemented by an overview of tenders and inquiries in different markets, to evaluate possible gains and losses by choosing to go further to develop a bid. 
The second step we have called "estimating". It is to be released from a decision to prioritize the project. The estimating can be done either directly as a detailed calculation of the various posts included in the project, or it may start as a rough estimation to come up with a preliminary guesstimate for a client to decide whether to go further with the project or not. The rough estimation will be developed from a list of geometric factors based on earlier bids, which are to be merged with cost components from our calculation program. It should be visualized in a BIM model, where the model can be used to communicate, analyse and evaluate different solutions with the client. The detailed calculation is a more comprehensive business. It includes estimating costs for the inhouse production and for the rigging and management of the construction site, besides adding incoming bids from subcontractors and suppliers to the calculus. As part of the estimating, we consider opportunities and risks - be they technical, commercial, contractual or progress related - to be measured and actions to be formulated to reduce the uncertainties. In the end, the bid will be submitted after a final review where the price, together with the project content and design, is locked.

The third and last step we have called "learning", which is to take place after the bid is submitted. It will be based on the ambition to continually learn and improve from what we do. To learn from the process, we will follow up closely with the client to clarify confusions and issues that need further explanation. Furthermore, we will invite the bidding team to do an evaluation of the bidding process. The evaluation will be supplemented by information from the competition, such as regarding assignment criteria and the ranking of bidders, feedback from the client and so on, which are to be utilized as part of considering which projects to prioritize next.

\section{ROUGH ESTIMATION USING TARGET VALUE DESIGN}

The unique nature of a construction project poses challenges to accurate estimation. At the same time, there is a relatively high degree of repeatability in some of the products we deliver. Particularly so, in resident housing projects. For a real estate developer who invests in a piece of land, the decision to do so is likely spurred by fiscal motives. Before buying the land, certain enquiries are usually needed about the product to be localized there. Some of these enquiries will typically include a contractor's opinion. In the following, we describe the process of developing a rough estimation as a response to these enquiries, where using target value design (TVD) - including choosing-byadvantages (CBA) and virtual first-run studies (VFRS) - can provide this process with the kind of structure it lacks according to today's practice.

Target value design in the early stage of developing a construction project is unusual since it will be performed before a budget is set. Nonetheless, in our experience the client may still have a relatively clear idea of what he or she is willing and able to spend to achieve the project (allowable cost). At the same time, spending no more than necessary can help to spur innovation in a way that contribute to reduce the actual costs in the project. When a client meets with a contractor on an early basis, he or she normally has a scope and some constraints on money, time and otherwise which set limits to what can be achieved through the project. As part of the rough estimation process, we wish to inquire 
a specification by the client to narrow down the alternatives. Using TVD, cost is applied as input instead of an output in the early design stage. Indeed, sometimes a client may already have met with an architect and even bring to the table some early sketches of what he or she wants, while in other instances the client does only have a rough idea. No matter the level of detailing, we think it might be useful to introduce CBA at this point to support the client in making sound decisions, by limiting the set of alternatives to select from.

When we have gained a relatively clear idea of the factors, criteria and attributes of the alternatives that the client has, we want to perform first-run studies to help the client decide which of the alternatives is the most valuable to him or her by evaluating their geometric, quality and not least cost related consequences in virtual mock ups. The client will in this way be able to walk through the virtual models to decide the best option to fit his or her requirements, he or she may choose to change the scope to get more value from the project, to reduce the scope or even kill the project. An essential benefit from our perspective is that we will spend more time to become familiar with the project, which in turn may lower the risks and their related cost implications.

\section{APPLYING BIM TO REDUCE UNCERTAINTY IN THE BIDDING WORK}

Adopting BIM to the bidding process we suspect may greatly improve the understanding of the project at an early stage as well as contributing to the effectiveness of the process itself. A building information model characterizes the geometry, spatial relationships, geographic information, quantities and properties of building elements, cost estimates, material inventories, and project schedule (Azhar 2011). As part of the bidding work, a BIM model can be used for cost estimation and quantity take-offs. The model can also be applied to visualize the timeline for the construction work as well as to detect potential conflicts, interferences and collisions. A BIM model may thus allow us to collaborate more accurately and efficiently in the bidding process, which in turn can work to reduce the uncertainty of the bid.

When every project (and bid) has a BIM model with its own calculation attached, we risk possessing many sets of data with differing cost information on the same or similar objects. Data clustering, or the division of a set of objects into groups of similar objects, will therefore be important to standardize the information. The task of data clustering is to divide a set of data into sub sets containing similar data (Veenhuis and Köppen 2006). When this is properly done, we hope to be able to model the behaviour of specific objects in various virtual environments without modelling each single object explicitly. For instance, when developing a rough estimation of a point house where the client wants to maximize noise considerations. Then, we want to be able to include in the calculation factors like the amount of saleable square meters, west facing balconies and so on. Applying CBA at this point will help us decide the advantages and importance of each of the alternatives, evaluate the cost data and identify the most workable alternative.

Data clustering, or data swarm clustering, is inspired from nature resembling the aggregation of animals, i.e. flock of birds, schools of fish and so on, where to maintain the structure of the swarm each swarm-mate behaves according to certain rules such as 
keep close to your neighbours or avoid collisions (Veenhuis and Köppen 2006). Applying BIM to the bidding work, the implementation of discrete rules is likewise important to be able to properly evaluate the cost and design consequences of different choices in virtual mock-ups using First-Run Studies. For instance, when the client plans a housing project with a garage for all the residents, where he or she wants to consider the cost and design consequences of placing it below or above ground. Then there needs to be certain rules established, in example as to where to place the costs of the ground floor so that prices are comparable before the benchmarking is done. If rules are not established, we risk (still) to be highly dependent of the tacit knowledge of the single calculator about how to calculate these costs.

\section{DISCUSSION: WINNING EVERY TIME - A VIABLE STRATEGY?}

The nature of competitive bidding is like a game where you win from time to time, and loose every so often. However, each bidding process starts with the ambition to succeed. Thus far, winning every time may say to be a viable strategy in construction bidding. At the same time, a general contractor is often bounded by factors which are likely to affect his or her behaviour in ways that influence the price - and thereby also the propensity to win so that winning every time is only viable to a certain point. In the following, we suggest grouping these factors in three major categories; the winner's curse, the capacity challenges and the competitive edge, where we discuss how to handle their related uncertainties by using our step-wise approach to construction bidding.

\section{The winner's curse}

The winner's curse involves the tendency for the winner in a low-bid-wins auction to be the one who underestimates his or her costs the most (Seydel and Olson 2001). Indeed, while underestimation can be the result of a calculated risk for reasons we will get back to in the next sections, we will here discuss it as something unwanted. The problem may start already in the prioritizing. Unless you have carefully considered your winning strategy, the risk of overexertion can be ubiquitous. The victory may thus be with an ugly taste. Bidding too low, and winning, is a quite common phenomenon in competitive bidding. By introducing the step-wise approach, involving analyses of uncertainties, decision points and learnings from earlier projects and bids, we hope to reduce the possibility of ending up by the winner's curse. But because of the clients' inclination to choose the lowest bid, this may also prevent us from winning the bid - while simultaneously it increases the possibility for someone else to end up by the winner's curse. A more fundamental way to avoid ending up by the winner's curse could be to decide a fixed mark-up, and never go below a certain profit margin when projects are being calculated. No matter what, it does not prevent the risk of underestimation as a malfunction, in example when costly factors are undervalued in the calculation. For a general contractor to distinguish between simple and complex elements can be a recurring challenge, with the subsequent pricing of simple things as too expensive and complex things as too low-priced. By applying BIM to the estimation of costs we expect 
to promote a more complete understanding of the project in the bidding team, so that errors and the subsequent mispricing will be a limited problem.

\section{The capacity challenges}

A general contractor calculates projects to get jobs. The jobs vary in size. What is more, they tend to come in an unregular fashion. This is the basis for the capacity challenges. Whether due to under- or overcapacity, the problem may have differing consequences on the price. When a general contractor is in need for work, he or she may lower the profit margins to produce a more competitive bid. This is a situation where one might end up by the winner's curse, but where there is a calculated risk behind the bidding behaviour. The contractor's reasoning for lowering the mark-up, apart from the obvious need for work, can also include less risk taking due to more in-house production as opposed to extensive use of hired labour. Under-capacity, on the other hand, can work to raise the mark-up in the bid. Not necessarily because of the apparent advantageous situation of having a full order book, since in the construction industry this is normally a very temporary state of being. Rather, it is the decision to bid still, for instance to maintain a strong position in a market, where due to the lack of productive capacity in-house one is forced to base the bid on a massive hiring of personnel. A step-wise approach to develop a bid does not rule out these capacity challenges. However, a thorough evaluation of the capacity situation should be included in the prioritizing and estimating of jobs, to make the right choice whether to go further to bidding and to decide the right level of the mark-up based on the risks involved.

\section{The competitive edge}

If the focus was solely on winning, then a rational strategy for a general contractor - at least on a short-term basis - would be to concentrate all the efforts in one or a very few markets where he or she holds a strong position because here the propensity to win every bid would be high. Being a general contractor, however, involves keeping the ability to meet the demands of various markets. This is because in a longer-term perspective markets fluctuate, and they may do so in an unsynchronized manner. The competitive edge for a general contractor lies thus in a combination of capabilities. The situation can be compared with the ambition to become a decent tennis player. The game of tennis is a very complicated business, much because it requires a set of skills to win. You may cultivate certain skills such as your serves and, indeed, come a long way, but to become a complete tennis player you must be able to handle numerous circumstances since you never know exactly where the next ball will come. For a general contractor, competencies are worked up through projects - much like a tennis player's skills are developed by playing the game. In terms of prioritizing bids, one may want to lower a bid and accept a reduced profit on a short-term project basis (winner's curse), if the longer-run strategy is market penetration or to strengthen the position in specific markets. Especially so, when a lower profit in some segments can be compensated by a higher income in other segments. Extremely important here (as in every instance) would be to communicate to those who will execute the project, the conditions behind the project calculation. 


\section{CONCLUSION}

In this paper we have explained how to win a bid at the right costs. We propose a stepwise approach supported by BIM, to reduce uncertainty in construction bidding. Since we are in the middle of testing and developing further some of the ideas, we are not yet able to conclude about the workability of the approach. Particularly so, when it comes to target value design and its belonging processes related to structured decision-making (CBA) and virtual mock-ups (VFRS). Their implementation will represent a significant effort in the case company to standardize the bidding process. In the paper we have also discussed how construction bidding is not a straightforward matter. The inclination to maximize the outcome, as emphasized in competitive bidding theory, is here contradicted by an alternative view where considerations such as the need for work, market penetration, and in-house competencies lead us to conclude that the general contractor is boundedly rational in his or her bidding behaviour.

\section{REFERENCES}

Azhar, S. (2011). Building Information Modelling (BIM): Trends, Benefits, Risks, and Challenges for the AEC Industry. Leadership and Management in Engineering, July 2011, 241-252.

Beckert, J. (1996). What is sociological about economic sociology? Uncertainty and the embeddedness of economic action. Theory and Society, December 1996, 25(6), 803840 .

Chao, L-C., and Liu, C-N. (2007). Risk-minimizing approach to bid-cutting limit determination. Construction Management and Economics, 25(8), 835-843.

Cheung, S. O., Wong, P. S., Fung, A., and Coffey, W. V. (2008). Examining the use of bid information in predicting the contractor's performance. Journal of Financial Mangement of Property and Construction, 13(2), p. 111-122.

Crowley, L. G. (2000). Friedman and Gates - Another Look. Journal of Construction Engineering and Management, 126(4).

Friedman, L. (1956). A Competitive-Bidding Strategy. Operation Research, 4(1).

Gates, M. (1967). Bidding Strategies and Strategies. Journal of Construction Division, 1967, 93(1), 75-110.

Hartono, B. and Yap, C. M. (2011). Understanding risky bidding: a prospectcontingent perspective. Construction Management and Economics, 29(6), 579-593.

Ribeiro, J. A., Pereira, P. J., and Brandão, E. (2013). Reaching an Optimal Mark-Up Bid through the Valuation of the Option to Sign the Contract by the Selected Bidder. SSRN, May 2013.

Runeson, G., and Skitmore, M. (1999). Tendering theory revisited. Construction Management and Economics, 17(3), 285-296.

Seydel, J., and Olson, D. L. (2001). Multicriteria Support for Construction Bidding. Mathematical and Computer Modelling, 34, 677-702.

Simon, H. A. (1957). Models of man; social and rational. Oxford, England, Wiley.

Tommelein, I., and Ballard, H. G. (2016). Lean Construction Glossary. P2SL, Berkeley. 
Tommelein, I., and Ballard, H. G. (2016). Target Value Design. Manual of Practice. Lean Design Forum, 28-29. January 2016.

Veenhuis, C., and Köppen, M. (2006). Data Swarm Clustering. Abraham A., Grosan C., Ramos V. (eds.). Swarm Intelligence in Data Mining. Studies in Computational Intelligence, 34. Springer, Berlin, Heidelberg.

Zhu, C. (2008). Rationality in bidding theory: a construction industry perspective. In Casensky, M. et al (eds). Proceedings BuHu $8^{\text {th }}$ International Postgraduate Research Conference, 2(1), 257-264. 